\title{
Landscape based identification of human disturbance gradients and reference conditions for Michigan streams
}

\author{
Lizhu Wang • Travis Brenden · Paul Seelbach • \\ Arthur Cooper • David Allan • Richard Clarck Jr. • \\ Michael Wiley
}

Published online: 17 July 2008

(C) Springer Science + Business Media B.V. 2008

\section{Erratum to: Environ Monit Assess (2008) \\ 141:1-17 \\ DOI 10.1007/s10661-006-9510-4}

The values and units for total nitrogen loading, total nitrogen yield, total phosphorus loading, and total phosphorus yield in the original Table 1 are incorrect. The original Table 1 should be replaced with the following table.

The online version of the original article can be found at doi: 10.1007/s10661-006-9510-4.

L. Wang $(\varangle) \cdot$ T. Brenden · P. Seelbach ·

A. Cooper · R. Clarck Jr.

Institute for Fisheries Research,

Michigan Department of Natural Resources,

University of Michigan, 212 Museums Annex,

1109 N. University, Ann Arbor, MI 48109, USA

e-mail: lizuwang@umich.edu

D. Allan · M. Wiley

School of Natural Resources and Environment,

University of Michigan, Ann Arbor, MI 48109, USA

Present Address:

T. Brenden

Quantitative Fisheries Center,

Department of Fisheries and Wildlife,

Michigan State University,

153 Giltner Hall, East Lansing, MI 48109, USA 
Table 1 Mean and range of human disturbance factors for all stream reaches in Michigan, from which disturbance variables were selected and disturbance thresholds were determined

\begin{tabular}{|c|c|c|c|c|}
\hline \multirow[t]{2}{*}{ Disturbance variable } & \multirow[t]{2}{*}{ Mean } & \multirow[t]{2}{*}{ Range } & \multicolumn{2}{|c|}{ Threshold } \\
\hline & & & Cold & Warm \\
\hline \multicolumn{5}{|l|}{ Variables selected for coldwater dataset: } \\
\hline Total nitrogen plus (phosphorus $\times 10)$ yield $\left(\mathrm{kg} / \mathrm{km}^{2} /\right.$ year) & 1,400 & $120-9,824$ & 800 & 2,000 \\
\hline \multicolumn{5}{|l|}{ Variables selected for warmwater dataset: } \\
\hline Dam density (\#/100 km²) & 1 & $0-278$ & 17.5 & 4.0 \\
\hline $\begin{array}{l}\text { USEPA's toxic release inventory sites discharging into } \\
\text { surface water }\left(\# / 10,000 \mathrm{~km}^{2}\right)\end{array}$ & 5 & $0-7,959$ & 10.0 & 10.0 \\
\hline \multicolumn{5}{|l|}{ Variables selected for coldwater and warmwater dataset: } \\
\hline Active mining $\left(\# / 10,000 \mathrm{~km}^{2}\right)$ & 3 & $0-5,948$ & 0.01 & 10.0 \\
\hline Network watershed agricultural land use (\%) & 36 & $0-100$ & 60 & 65 \\
\hline Network watershed urban land use (\%) & 5 & 0-92 & 8 & 8 \\
\hline MDEQ's permitted point source facilities $\left(\# / 100 \mathrm{~km}^{2}\right)$ & 6 & $0-757$ & 10.0 & 16.0 \\
\hline $\begin{array}{l}\text { MDEQ's permitted point source facilities having direct } \\
\text { connection with stream }\left(\# / 100 \mathrm{~km}^{2}\right)\end{array}$ & 1 & $0-759$ & 3.0 & 6.1 \\
\hline USEPA's toxic release inventory sites $\left(\# / 10,000 \mathrm{~km}^{2}\right)$ & 55 & $0-21,808$ & 10.0 & 150.0 \\
\hline Population density $\left(\# / \mathrm{km}^{2}\right)$ & 49 & $0-2,273$ & 50 & 200 \\
\hline Road crossing $\left(\# / \mathrm{km}^{2}\right)$ & 1 & $0-16$ & 0.6 & 0.6 \\
\hline Road density $\left(\mathrm{km} / \mathrm{km}^{2}\right)$ & 2 & $0-14$ & 2.2 & 2.5 \\
\hline Total nitrogen plus (phosphorus $\times 10)$ loading $(\mathrm{kg} /$ year) & 13,918 & $735-49,934$ & 950 & 6,000 \\
\hline Watershed area treated with manure from barn yards $(\mathrm{m} / \mathrm{km})$ & 1 & $0-8$ & 1.3 & 0.1 \\
\hline \multicolumn{5}{|l|}{ Disturbance factors that were not selected: } \\
\hline Local buffer agricultural land use (\%) & 25 & $0-100$ & 30 & 25 \\
\hline Local buffer urban land use (\%) & 5 & $0-100$ & 3.8 & 6 \\
\hline Local watershed agricultural land use (\%) & 33 & $0-100$ & 60 & 65 \\
\hline Local watershed urban land use (\%) & 5 & $0-100$ & 4 & 6 \\
\hline Network buffer agricultural land use (\%) & 29 & $0-100$ & 30 & 35 \\
\hline Network buffer urban land use (\%) & 4 & 0-90 & 3.8 & 6 \\
\hline Total nitrogen loading (kg/year) & 8,123 & $501-30,696$ & 6,500 & 6,500 \\
\hline Total nitrogen yield $\left(\mathrm{kg} / \mathrm{km}^{2} /\right.$ year $)$ & 788 & $86-2,900$ & 430 & 1,200 \\
\hline Total phosphorus loading (kg/year) & 580 & $23-3,370$ & 320 & 300 \\
\hline Total phosphorus yield $\left(\mathrm{kg} / \mathrm{km}^{2} /\right.$ year $)$ & 61 & $3-692$ & 25 & 105 \\
\hline Watershed area treated with fertilizers (\%) & 20 & $0-58$ & 9.0 & 30.0 \\
\hline Watershed area treated with herbicides and insecticides (\%) & 19 & $0-62$ & 6.8 & 30.0 \\
\hline Watershed area treated with manure (\%) & 2 & $0-9$ & 3.5 & 2.8 \\
\hline \multicolumn{5}{|l|}{ Covariance variables included in the analysis: } \\
\hline Watershed size $\left(\mathrm{km}^{2}\right)$ & 55 & $0.5-1,598$ & NA & NA \\
\hline Gradient $(\mathrm{m} / \mathrm{km})$ & 5 & $0-110$ & NA & NA \\
\hline
\end{tabular}

The threshold value for each disturbance factor was the level of disturbance beyond which fish variables showed apparent impacts, which was visually determined by plotting each disturbance factor against values of index of biotic integrity and percent intolerant fish individuals

USEPA U.S. Environmental Protection Agency, $M D E Q$ Michigan Department of Environmental Quality 